\title{
The role of neutropenia on outcomes of cancer patients with community-acquired
} pneumonia

\author{
S. Aliberti*,\#, J.A. Myers ${ }^{\star}$, P. Peyrani ${ }^{*}$, F. Blasi*, R. Menendez ${ }^{+}$, P. Rossi $^{\S}$, \\ R. Cosentini ${ }^{f}$, G. Lopardo**, L. de Vedia ${ }^{\# \#}$ and J.A. Ramirez ${ }^{\#}$
}

ABSTRACT: Although the presence of neutropenia may predispose cancer patients to develop community-acquired pneumonia, the role of neutropenia on their outcomes has not been investigated. The purpose of the present study was to compare clinical outcomes of cancer community-acquired pneumonia patients with and without neutropenia.

Patients with cancer, identified in the Community-Acquired Pneumonia Organization database, were divided into two groups according to the type of cancer and the presence of neutropenia: patients with solid cancer without neutropenia versus those with functional or absolute neutropenia. Among the 3,106 community-acquired pneumonia patients enrolled, 135 had cancer without neutropenia and 75 had cancer with neutropenia.

No significant difference was found between patients with and without neutropenia regarding mean time to clinical stability ( $5.4 \pm 2.7$ versus $4.9 \pm 2.7$ days, respectively), mean length of hospital stay (9.2 \pm 7.7 versus $9.9 \pm 9.6$ days) and in-hospital mortality (18 versus 15\%, respectively). Using a multiple logistic regression model, neutropenia was not associated with mortality in cancer patients when adjusting for significant covariates (odds ratio 1.30).

Lack of neutropenia, during the initial evaluation of a cancer community-acquired pneumonia patient, should not be considered an indicator of better clinical outcome.

\section{KEYWORDS: Cancer, community-acquired pneumonia, neutropenia, outcomes}

(CAP) nfectious diseases account for high morbidity and mortality in patients with cancer and, among them, community-acquired pneumonia (CAP) represents the most common and lifethreatening disease [1-3]. The development of $\mathrm{CAP}$ in cancer patients can be due to an alteration of the immune-defence mechanisms resulting from either the malignancy or its treatment. The risk of infection, due to the nature of cancer, can be associated with humoral immune deficit, cellular immune deficit or neutrophil disorders. Haematological malignancies can predispose patients to infections because of the replacement of the marrow with malignant cells. Consequently, these patients have functional neutropenia even though they may have normal or even increased numbers of neutrophils. Moreover, cancer patients may experience neutropenia as a side effect of chemotherapy or radiotherapy (absolute neutropenia).

The degree of neutropenia has been considered the single most important factor contributing to infection in cancer patients, particularly when the neutrophil count drops below 500 cells $\cdot \mathrm{mm}^{-3}$ $[4,5]$. The overall mortality recorded in febrile neutropenic patients with cancer is $30-50 \%$ [6]. During the past two decades, treatment of infections in the cancer population has been primarily focused on the management of fever and neutropenia, due to the fact that the site of infection cannot be determined in $50-80 \%$ of cancer patients $[7,8]$.

The American Thoracic Society guidelines for the management of CAP, published in 2001, used neutropenia in order to identify more severe cancer patients with CAP [9]. Patients with haematological malignancy, experiencing functional neutropenia, or patients affected by any type of cancer and having absolute neutropenia were excluded from the guidelines. The decision to include patients with solid cancer without neutropenia in the guidelines was based only on expert opinions. Due to this, physicians may feel

\section{AFFILIATIONS}

*Institute of Respiratory Disease, University of Milan, Ospedale Maggiore Fondazione IRCCS Policlinico, Mangiagalli e Regina Elena, and

${ }^{\dagger}$ Emergency Medicine Dept, Ospedale Maggiore Fondazione IRCCS Policlinico, Mangiagalli e Regina Elena, Milan, and

${ }^{\S}$ Division of Internal Medicine, Dept of Medicine, Azienda Ospedaliera "S Maria della Misericordia", Udine, Italy. \#Division of Infectious Diseases, Dept of Medicine, University of Louisville, and 'Dept of Bioinformatics and Biostatistics, School of Public Health and Information Sciences, University of Louisville, Louisville, Kentucky, USA.

+Pneumology Service, La Fe University Hospital, Valencia, Spain.

** Division of Infectious Diseases, Dept of Medicine, Hospital Bernardo Houssay, and

${ }^{\# \# H o s p i t a l ~ F r a n c i s c o ~ J . ~ M u n ̃ i z, ~ B u e n o s ~}$ Aires, Argentina.

\section{CORRESPONDENCE}

J.A. Ramirez, Division of Infectious

Diseases, Dept of Medicine, University of Louisville, Louisville, KY, USA.

Fax: 15028521147

E-mail: j.ramirez@louisville.edu

Received:

December 132007

Accepted after revision:

September 162008

This work won the Young Researcher Award at the 2007 ERS Annual Congress. This poster was accepted and presented as a poster at the 2007 ERS Annual Congress. 
confident in treating cancer patients without neutropenia as regular patients with CAP. However, the role that neutropenia may have in clinical outcomes of cancer patients hospitalized with CAP has not yet been investigated.

In order to better define clinical outcomes of cancer patients hospitalised for an episode of CAP, the present study had the following objectives: 1) to compare clinical outcomes in cancer patients versus immunocompetent patients; 2) to compare clinical outcomes in cancer patients with absolute or functional neutropenia versus those without neutropenia.

\section{MATERIALS AND METHODS Study design and subjects}

A secondary analysis of the Community-Acquired Pneumonia Organization (CAPO) database was performed. The database contains data retrospectively collected from 43 hospitals in 12 countries between June 2001 and January 2006. In each participating centre, primary investigators selected nonconsecutive adult hospitalised patients diagnosed with CAP. All data were collected on a case report form and transferred electronically to the CAPO co-ordinating centre at the University of Louisville (Louisville, KY, USA). A sample of the study protocol and the data collection forms are available at the study website [10]. Discrepancies and inconsistencies in the data were determined at the co-ordinating centre. After all queries were clarified, cases were entered into the database. Local institutional review board approval was obtained for each study site.

\section{Inclusion and exclusion criteria}

Patients aged $\geqslant 18$ yrs and satisfying the criteria for CAP were included in the study. In order to investigate primarily immunosuppression due to cancer, patients with a diagnosis of HIV infection were excluded.

\section{Study definition}

CAP was defined as the presence of a new pulmonary infiltrate on chest radiograph at the time of hospitalisation associated with at least one of the following: 1) new or increased cough; 2) an abnormal temperature $\left(<35.6\right.$ or $\left.>37.8^{\circ} \mathrm{C}\right)$; 3$)$ an abnormal serum leukocyte count (leukocytosis, left shift or leukopenia defined by local laboratory values).

Cancer was defined as any type of malignancy that was diagnosed in the previous 12 months or as active cancer. Active cancer was considered to be present in patients who had received chemotherapy and/or radiotherapy in the previous 12 months or in patients who exhibited signs or symptoms of cancer during the past year. Patients with basal or squamous cell cancer of the skin were considered immunocompetent.

Neutropenia was defined as functional or absolute neutropenia. Functional neutropenia was considered present in all patients affected by haematological malignancy. Absolute neutropenia was defined as an absolute neutrophils count $\left(\right.$ ANC) $<500$ cells $\cdot \mathrm{mm}^{-3}$ on admission. Neutropenia was not considered in patients with a septic state.

\section{Study groups}

Patients with CAP were divided into two groups according to the presence of cancer: subjects without cancer, "Group 1", and subjects with cancer, "Group 2". Patients in Group 2 were divided into two subgroups according to the type of cancer and the presence of neutropenia: patients with solid cancer without neutropenia, "Group 2a", and patients with neutropenia, "Group $2 b^{\prime \prime}$.

\section{Outcomes}

Mortality, length of stay and time to clinical stability (TCS) were considered as outcomes and their definitions are presented in the online data supplement.

\section{Statistical analysis}

Descriptive statistics were reported at baseline with continuous data expressed as a mean $\pm \mathrm{SD}$ and categorical data expressed as counts. Patient characteristics were compared between Group 1 and Group 2 and between Group 2a and Group 2b. Summary statistics for all continuous explanatory variables are presented as means with differences between the two groups compared by means of independent unpaired $\mathrm{t}$ tests. Categorical explanatory variables are summarized as frequencies and percentages with differences between the two groups analysed using the chi-squared test. A p-value $\leqslant 0.05$ was considered statistically significant.

The one-way ANOVA technique followed by the Dunnett's post hoc comparison technique was initially used to compare mortality rates between Group 1, Group 2a and Group 2b. The associations between mortality and cancer among the study population and between mortality and neutropenia among Group 2 were also studied using multiple logistic regression models. All the significant explanatory variables and those that were considered of clinical relevance were incorporated into the model by utilising multiple logistic regression techniques.

Differences between Group 1 and Group 2 and between Group $2 \mathrm{a}$ and Group $2 \mathrm{~b}$ were studied regarding time to clinical stability (TCS) and length of stay (LOS). A univariate analysis of comparing mean LOS and TCS was performed. Differences were further assessed with the Kaplan-Meier method, the logrank test and Cox regression analysis.

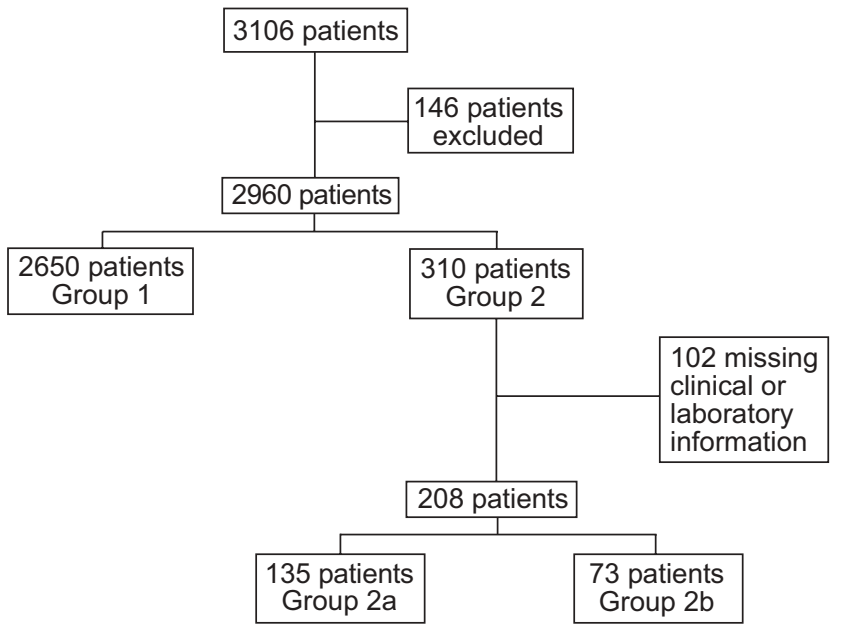

FIGURE 1. The study flow chart. Group 1: community-acquired pneumonia (CAP) patients without cancer. Group 2: CAP patients with cancer. Group 2a: CAP patients with solid cancer without neutropenia. Group 2b: CAP patients with neutropenia. 


\section{RESULTS}

A total of 3,106 patients with CAP were enrolled during the study period. The study flow chart is shown in figure 1 .

\section{Characteristics of patients with and without cancer}

Demographics, comorbidities, severity of the disease, clinical, laboratory and radiological findings of the study population on admission according to the presence of cancer are summarised in table 1.

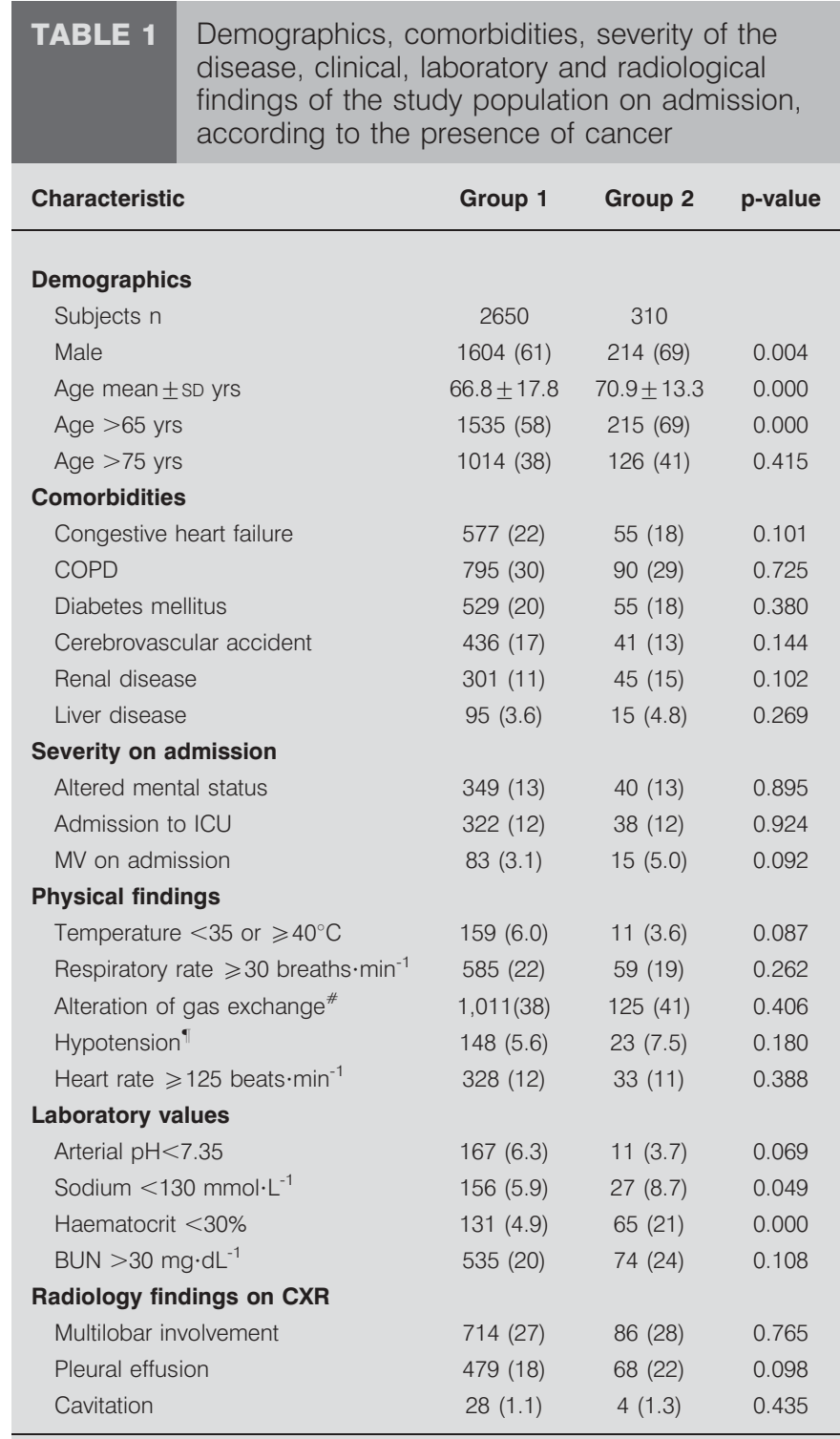

Data are presented as n (\%), unless otherwise stated. Group 1: communityacquired pneumonia (CAP) patients without cancer; Group 2: CAP patients with cancer; COPD: chronic obstructive pulmonary disease; ICU: intensive care unit; MV: mechanical ventilation; BUN: blood urea nitrogen; CXR: chest radiograph. \#: arterial oxygen tension $<60, \mathrm{~Pa}_{1} \mathrm{O}_{2} /$ inspiratory oxygen fraction $<300$ or oxygen saturation $<90 \%$; $"$ : systolic blood pressure $<90 \mathrm{mmHg}$ or diastolic blood pressure $<60 \mathrm{mmHg}$.
Distribution of the type of cancer among patients in Group 2 is shown in table 2. A co-existence of malignancy affecting two different organs was found in three patients.

\section{Outcomes of patients with and without cancer}

The mortality rate was significantly higher in patients with cancer when compared with patients without cancer (43 out of 310 patients, $14 \%$ versus 213 out of $2,650,8.0 \%$, respectively; $\mathrm{p}=0.001)$. In the $13(30 \%)$ out of 43 patients among those with cancer who died, mortality was considered to be related to CAP. Using multiple logistic regression methods, this result was consistent: the presence of cancer on admission among the study population was found to significantly impact mortality when adjusting for significant covariates (odds ratio (OR) 1.63, $95 \%$ confidence interval $(\mathrm{CI}) 1.08-2.45 ; \mathrm{p}=0.020)$.

In comparison to patients without cancer, those with cancer had a significantly longer TCS $(4.6 \pm 2.5$ days versus $5.1 \pm 2.6$ days, respectively; $p=0.001)$ and LOS $(8.4 \pm 4.7$ days versus $9.3 \pm 4.8$ days, respectively; $p=0.001)$. Using the Kaplan-Meier and log-rank methods, cancer on admission was found to significantly impact both TCS (Log rank Chisquared 12.45; $\mathrm{p}<0.0001$ ) and LOS (Log-rank Chi-squared $10.87 ; \mathrm{p}=0.001)$.

\section{Characteristics of cancer patients with and without neutropenia}

Baseline demographics, comorbidities, severity of the disease, clinical, laboratory and radiological findings among cancer patients stratified by neutropenia are summarised in table 3.

Outcomes of cancer patients with and without neutropenia The mean TCS was similar between cancer patients with and without neutropenia $(5.4 \pm 2.7$ versus $4.9 \pm 2.7$ days, respectively; $p=0.264)$. Using the Kaplan-Meier and log-rank methods to evaluate TCS, no statistical difference was found between the two groups (Log rank Chi-squared 0.859; $\mathrm{p}=0.354$; fig. 2). This result held consistent after adjustment for significant explanatory variables included in the logistic model (hazard ratio (HR) 0.911, 95\% CI 0.664-1.251; $\mathrm{p}=0.566$ ).

\section{TABLE 2 Type of malignancy in group of patients with} cancer (Group 2)

\begin{tabular}{lccc} 
Solid tumour & $\begin{array}{c}\text { Patients } \\
\mathbf{n}\end{array}$ & $\begin{array}{c}\text { Haematological } \\
\text { malignancy }\end{array}$ & $\begin{array}{c}\text { Patients } \\
\mathbf{n}\end{array}$ \\
\hline Lung cancer & 60 & Leukaemia & 22 \\
Prostate cancer & 18 & Non-Hodgkin's lymphoma & 15 \\
Breast cancer & 14 & Multiple myeloma & 12 \\
Head and neck cancer & 11 & Myelodisplasia & 10 \\
Bladder cancer & 8 & Hodgkin's lymphoma & 3 \\
Colon cancer & 8 & Aplastic anaemia & 2 \\
Kidney cancer & 4 & Policytemia vera & 2 \\
Gastric cancer & 3 & Other & 5 \\
Cervical cancer & 2 & & \\
Pancreatic cancer & 2 & & \\
Other & 9 & & \\
\hline
\end{tabular}




\begin{tabular}{|c|c|c|c|c|}
\hline \multirow{2}{*}{$\begin{array}{l}\text { TABLE } 3 \\
\text { Characteris }\end{array}$} & \multicolumn{4}{|c|}{$\begin{array}{l}\text { Demographics, comorbidities, severity of the } \\
\text { disease, clinical, laboratory and radiological } \\
\text { findings on admission of the cancer population, } \\
\text { according to the presence of neutropenia }\end{array}$} \\
\hline & & Group 2a & Group 2b & p-value \\
\hline \multicolumn{5}{|c|}{ Demographics } \\
\hline Subjects $n$ & & 135 & 73 & \\
\hline Male & & $105(78)$ & $51(70)$ & 0.208 \\
\hline Age mean & SD yrs & $71.3 \pm 12.8$ & $68.3 \pm 14.6$ & 0.126 \\
\hline Age $>65$ & & $94(70)$ & $44(60)$ & 0.173 \\
\hline Age $>75$ & & $53(39)$ & $26(36)$ & 0.605 \\
\hline \multicolumn{5}{|c|}{ Comorbidities } \\
\hline Congestiv & heart failure & $30(22)$ & $18(25)$ & 0.691 \\
\hline COPD & & $47(35)$ & $14(19)$ & 0.018 \\
\hline Diabetes $n$ & litus & $26(20)$ & $12(16)$ & 0.582 \\
\hline Cerebrova & ular accident & $23(17)$ & $4(6)$ & 0.012 \\
\hline Renal dise & & $26(19)$ & $11(15)$ & 0.451 \\
\hline Liver disea & & $9(6.7)$ & $1(1.4)$ & 0.080 \\
\hline \multicolumn{5}{|c|}{ Severity on admission } \\
\hline Altered me & al status & $21(16)$ & $5(7)$ & 0.070 \\
\hline Admission & ICU & $21(16)$ & $9(12)$ & 0.501 \\
\hline MV on adr & ssion & $7(5.2)$ & $4(6.2)$ & 0.505 \\
\hline \multicolumn{5}{|c|}{ Physical findings } \\
\hline Temperatu & $<35$ or $\geqslant 40^{\circ} \mathrm{C}$ & $6(4.5)$ & $3(4.2)$ & 0.615 \\
\hline Respirator & ate $\geqslant 30$ breaths $\cdot \mathrm{min}^{-1}$ & $27(20)$ & $13(19)$ & 0.844 \\
\hline Alteration & gas exchange $^{\#}$ & $56(42)$ & $29(41)$ & 0.930 \\
\hline Hypotensi & & $11(8.3)$ & $6(8.2)$ & 0.990 \\
\hline Heart rate & 125 beats $\cdot \mathrm{min}^{-1}$ & $20(15)$ & $6(11)$ & 0.458 \\
\hline \multicolumn{5}{|c|}{ Laboratory values } \\
\hline Arterial pH & 7.35 & $5(3.7)$ & $1(1.6)$ & 0.379 \\
\hline Sodium $<$ & $30 \mathrm{mmol} \cdot \mathrm{L}^{-1}$ & $9(6.7)$ & $11(15.3)$ & 0.046 \\
\hline Haematoc & $<30 \%$ & $15(11)$ & $29(41)$ & 0.000 \\
\hline BUN $>30$ & $g \cdot d^{-1}$ & $27(20)$ & $29(40)$ & 0.002 \\
\hline \multicolumn{5}{|c|}{ Radiology findings on CXR } \\
\hline Multilobar & volvement & $36(27)$ & $26(36)$ & 0.178 \\
\hline Pleural effi & & $32(24)$ & $17(23)$ & 0.946 \\
\hline Cavitation & & $3(2.2)$ & $0(0)$ & N/A \\
\hline \multicolumn{5}{|c|}{ Medical treatment } \\
\hline ABT Comp & ant to local guidelines & $116(88)$ & $51(85)$ & 0.583 \\
\hline Fluoroquin & one & $46(34)$ & $34(47)$ & 0.077 \\
\hline$\beta$-lactam & & $108(80)$ & $49(67)$ & 0.039 \\
\hline Macrolide & & $58(43)$ & $29(40)$ & 0.651 \\
\hline
\end{tabular}

Data are presented as n (\%), unless otherwise stated. Group 2a: communityacquired pneumonia (CAP) patients with solid cancer without neutropenia; Group 2b: CAP patients with functional or absolute neutropenia; COPD: chronic obstructive pulmonary disease; ICU: intensive care unit; MV: mechanical ventilation; BUN: blood urea nitrogen; CXR: chest radiograph. ${ }^{*}$ : arterial oxygen tension $\left(\mathrm{Pa}_{1} \mathrm{O}_{2}\right)<60, \quad \mathrm{~Pa}_{1} \mathrm{O}_{2} /$ inspiratory oxygen fraction $<300$ or oxygen saturation $<90 \%$; : systolic blood pressure $<90 \mathrm{mmHg}$ or diastolic blood pressure $<60 \mathrm{mmHg}$.

The mean LOS was similar between cancer patients with and without neutropenia $(9.2 \pm 7.7$ versus $9.9 \pm 9.6$ days, respectively; $p=0.638$ ). Using the Kaplan-Meier and log rank methods to evaluate LOS, no statistical difference was found between the two groups (Log rank Chi-sqaured 0.043; $\mathrm{p}=0.837$; fig. 3). This result held consistent after adjustment for

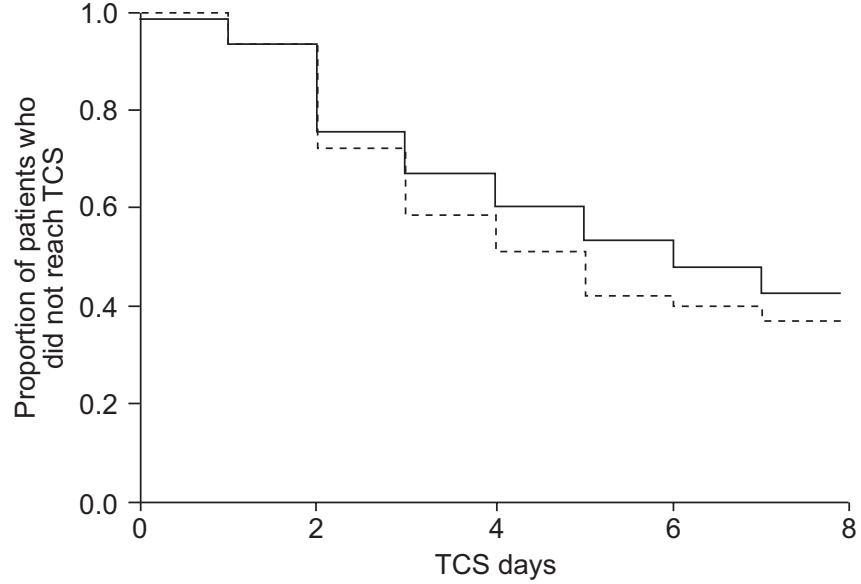

FIGURE 2. Kaplan-Meier survival curves for time to clinical stability (TCS) in community-acquired pneumonia patients with $(-)$ and without (------) neutropenia.

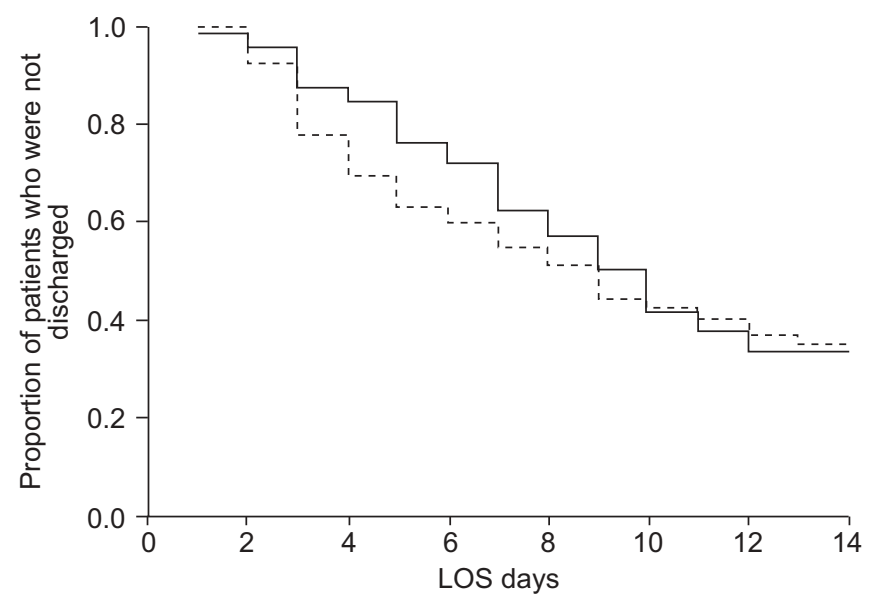

FIGURE 3. Kaplan-Meier survival curves for length of stay (LOS) in community-acquired pneumonia patients with (-) and without (-----) neutropenia.

significant explanatory variables included in the logistic model (HR 1.055, 95\% CI 0.779-1.430; $\mathrm{p}=0.728$ ).

The mortality of the study population according to the presence of neutropenia is shown in figure 4 . No significant difference in mortality rate was found in cancer patients with and without neutropenia (18 versus 15\%, respectively; $\mathrm{p}=0.573$ ). A significant difference in mortality was found between patients without cancer and both cancer patients without neutropenia ( 8 versus $15 \%$, respectively; $\mathrm{p}=0.006$ ) and with neutropenia (8 versus $18 \%$, respectively; $\mathrm{p}=0.003$ ).

Using a multiple logistic regression model, neutropenia was found to not be significantly associated to mortality in cancer patients (OR 1.56, 95\% CI 0.465-5.20; $\mathrm{p}=0.474$ ), when adjusting for significant covariates. When the stepwise procedure was applied to the full model, neutropenia did not survive the stepwise procedure, while CRB-65 (confusion, respiratory rate $\geqslant 30$ breaths $\cdot \mathrm{min}^{-1}$, low blood pressure (systolic value $<90 \mathrm{mmHg}$ or diastolic value $\leqslant 60 \mathrm{mmHg}$ ) and age $\geqslant 65 \mathrm{yrs}$ ) 


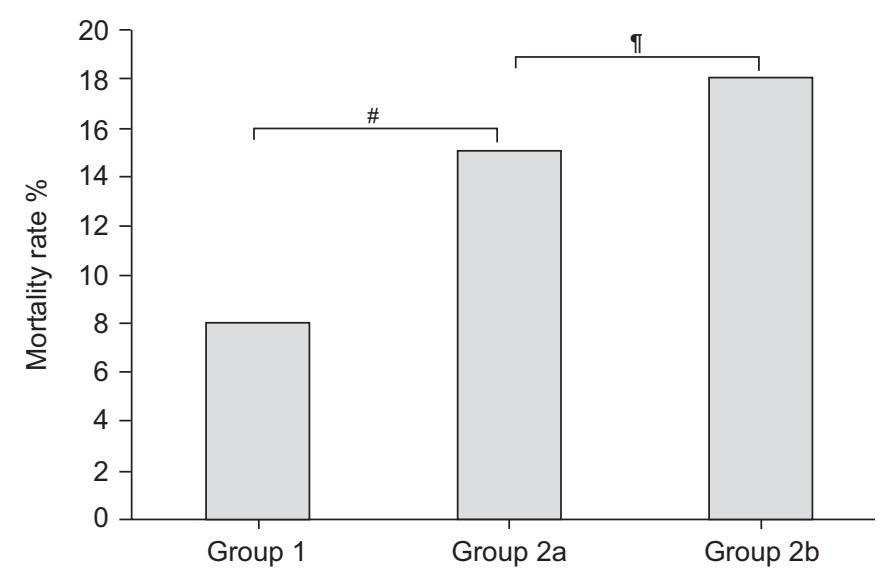

FIGURE 4. Mortality rate in the study population, presented in the cancer group according to the neutrophil status. Group 1: community-acquired pneumonia (CAP) patients without cancer; Group 2a: CAP patients with solid cancer without neutropenia; Group 2b: CAP patients with functional or absolute neutropenia. \#: $p=0.006 ; ": p=0.573$. The number of deaths in Group 1, 2a and 2b were 213, 20 and 13 , respectively. The number of patients in Group 1, 2a and 2b were 2,650, 135 and 73 , respectively.

did survive as independently associated with mortality (OR 4.59, 95\% CI 1.1-18.7; $\mathrm{p}=0.034$; fig. 5 and table 4 ).

\section{DISCUSSION}

This study indicates that, in patients with CAP, the presence of malignancy significantly increases mortality and worsens clinical outcomes. Among CAP patients with cancer, those without neutropenia have similar outcomes compared to those with neutropenia. The presence of neutropenia on admission was not an independent risk factor for mortality in patients with cancer undergoing an episode of CAP. The present findings suggest that physicians should aggressively manage cancer patients with $\mathrm{CAP}$, regardless of the type of cancer or the neutrophil count on admission. The lack of neutropenia during the initial evaluation of a cancer patient with CAP should not be considered an indicator of better clinical outcomes.

Although neutropenia is a key risk factor for infections, other factors seem to pose cancer patients with CAP at equal risk for poor outcomes. At least three considerations can explain the findings of the present study. First, even though patients with solid tumors may have a normal neutrophil count, cytotoxic drugs used for the treatment of cancer can affect chemotactic and phagocytic function, without reflecting on the total cell count. Secondly, the functional capabilities of phagocytes such as neutrophils, eosinophils and mononuclear cells may be intrinsically defective even before the initiation of chemotherapy. A study performed by HüBEL et al. [11] showed cancer patients having preactivated phagocytes with suppressed function prior to initiation of treatment. Thirdly, humoral and cellular immune mechanisms mediated by $\mathrm{B}$ and $\mathrm{T}$ lymphocytes, respectively, can be profoundly altered in patients with solid cancer. Multiple aspects of the host defence system can be simultaneously impaired in cancer patients hospitalised with CAP, thus influencing their outcomes. This mixed pattern of immunodeficiency may explain the lack of improved outcomes in the present patients without neutropenia.

\begin{tabular}{|c|c|c|c|}
\hline TABLE 4 & \multicolumn{3}{|c|}{$\begin{array}{l}\text { Multivariable analysis of mortality in patients with } \\
\text { community-acquired pneumonia and cancer }\end{array}$} \\
\hline \multicolumn{2}{|c|}{ Characteristic } & OR (95\% Cl) & p-value \\
\hline \multicolumn{2}{|c|}{ Neutropenia } & $1.282(0.5-3.6)$ & 0.638 \\
\hline \multicolumn{2}{|l|}{ COPD } & $1.344(0.5-3.6)$ & 0.553 \\
\hline \multicolumn{2}{|c|}{ Cerebrovascular accident } & $1.117(0.3-4.3)$ & 0.871 \\
\hline \multicolumn{2}{|c|}{ PSI Risk Class IV-V } & $1.018(0.2-5.1)$ & 0.983 \\
\hline \multicolumn{2}{|c|}{ CRB-65 Score 3-4 } & $4.585(1.1-18.7)$ & 0.034 \\
\hline \multicolumn{2}{|c|}{ BUN $>30 \mathrm{mg} \cdot \mathrm{mL}^{-1}$} & $0.926(0.3-2.5)$ & 0.926 \\
\hline \multicolumn{2}{|c|}{ Haematocrit $<\mathbf{3 0} \%$} & $0.757(0.3-2.2)$ & 0.612 \\
\hline \multicolumn{2}{|c|}{ Sodium $<\mathbf{1 3 0} \mathrm{mmol} \cdot \mathrm{L}^{-1}$} & $1.028(0.2-5.0)$ & 0.973 \\
\hline \multicolumn{2}{|c|}{ Compliant ABT } & $0.622(0.1-2.9)$ & 0.544 \\
\hline
\end{tabular}

OR: odds ratio; Cl: confidence interval; COPD: chronic obstructive pulmonary disease; PSI: pneumonia severity index; CRB-65: confusion, respiratory rate $\geqslant 30$ breaths $\cdot \mathrm{min}^{-1}$, low blood pressure (systolic value $<90 \mathrm{mmHg}$ or diastolic value $\leqslant 60 \mathrm{mmHg}$ ) and age $\geqslant 65 \mathrm{yrs}$; $\mathrm{BUN}$ : blood urea nitrogen; $\mathrm{ABT}$ : antibiotic therapy.

The results of the present study are consistent with recent literature which has questioned the role of neutropenia in outcomes of both haematological and solid tumours patients undergoing an infection. Neutropenia was not found to affect mortality in cancer patients with Streptococcus pneumoniae bacteraemia [12], as well as bacteraemia caused by other micro-organisms [13]. In line with these data, five other studies evaluating patients hospitalised in ICU showed neutropenia to not be independently associated with mortality in cancer patients with different sites of infection [14-18]. During the past decades, the attention in management of infections in cancer patients has focused on fever and neutropenia [19]. ToHohe latest guidelines published by the National Comprehensive Cancer Network, however, recommend that immunocompromised non-neutropenic cancer patients receive equal attention as those with neutropenia [20].

Neutropenia

COPD

Cerebrovascular accident

PSI Risk Class IV-V

CRB-65 Score 3-4

BUN $>30 \mathrm{mg} \cdot \mathrm{dL}^{-1}$

Haematocrit $<30 \%$

Sodium $<130 \mathrm{mmol} \cdot \mathrm{L}^{-1}$ Compliant ABT

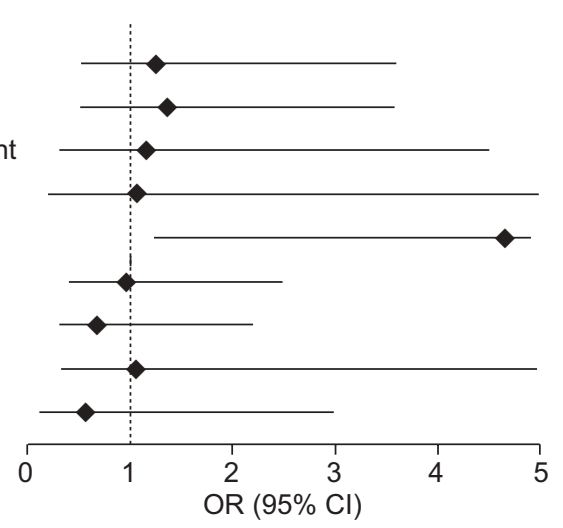

FIGURE 5. Multivariable analysis of mortality in patients with communityacquired pneumonia and cancer. All variables included in the model were dichotomised: yes versus no. OR: odds ratio; $\mathrm{Cl}$ : confidence interval; COPD: chronic obstructive pulmonary disease; PSI: pneumonia severity index; CRB-65: confusion, respiratory rate $\geqslant 30$ breaths $\cdot \mathrm{min}^{-1}$, low blood pressure (systolic value $<90 \mathrm{mmHg}$ or diastolic value $\leqslant 60 \mathrm{mmHg}$ ) and age $\geqslant 65 \mathrm{yrs}$; BUN: blood urea nitrogen; $A B T$ : antibiotic therapy. 
One important limitation of the present study, in evaluating the effect of neutropenia on clinical outcomes, is the lack of information regarding the duration of neutropenia before admission to the hospital, the development of neutropenia or the neutropenia recovery during hospitalisation. Moreover, in light of the fact that the present was a retrospective study, the authors were not able to collect more data on malignancies, neither on chemotherapies nor on bone marrow transplant. This study is strengthened by the large patient cohort involving 43 institutions in 12 different countries and by its use of an unselected population. The sample was composed of subjects admitted to general hospitals and not by those referring to specialised cancer facilities only.

In conclusion, the present data indicate that the lack of neutropenia in cancer patients hospitalised for CAP does not prevent poor clinical outcomes; therefore, physicians cannot be reassured of a better outcome when neutropenia is not present at the initial evaluation of a cancer patient with CAP. Thus, physicians should aggressively manage all cancer patients with $\mathrm{CAP}$, regardless of the type of cancer or the neutrophil count.

\section{ACKNOWLEDGEMENTS}

The CAPO investigators are as follows. R. Nakamatsu (Veterans Affairs Medical Center); F. W. Arnold and M. Allen (University Hospital); G. Broch (Dept of Bioinformatics and Biostatistics, University of Louisville, all Louisville, KY, USA); J. Bordon (Providence Hospital, Washington, DC, USA); P. Gross (Hackensack University Medical Center, Hackensack, NJ, USA); K. Weiss (Maisonneuve-Rosemont Hospital, University of Montreal, Montreal, Canada); D. Legnani (Ospedale L. Sacco, Milan, Italy); M. Bodi (Hospital Universitario Joan XXIII); J. Porras (Hospital Sant Pau i Santa Tecla, both Tarragona, Spain); A. Torres (Instituto de Neumonologia y Cirugia Toracica, Barcelona, Spain); H. Lode (City Hosp. E.v.Behring/Lungenklinik Heckeshorn, Berlin, Germany); J. Roig (Hospital Nostra Senyora de Meritxell, Escaldes, Andorra); G. Benchetrit (IDIM A. Lanari, Buenos Aires (BA)); J. Gonzalez (Hospital Enrique Tornu, BA); A. Videla (Hospital Universitario Austral, BA); J. Corral (Hospital Dr Oscar Alende, Mar del Plata); J. Martinez (Instituto Medico Platense, La Plata); E. Rodriguez (Hospital Espanol de La Plata, La Plata); M. Rodriguez (Hospital Rodolfo Rossi, La Plata); C. Victorio (Clinica Uruguay, Entre Rios, all Argentina); G. Levy (Hospital Universitario de Caracas, Caracas); F. Arteta (Hospital Luis Gomez Lopez-Ascardio, Barquisimeto, both Venezuela); A. Diaz Fuenzalida (Pontifica Universidad de Chile); M. Parada (Clinica las Condes, both Santiago, Chile); J. Luna (Hospital Nacional Roosevelt, Guatemala).

The authors acknowledge the assistance of M. E. Allen (Division of Infectious Diseases) and E. Smigielski (Kornhauser Health Sciences Library; both University of Louisville, Louisville, KY, USA).

\section{REFERENCES}

1 Annual report on trends in the health of Americans. Health, United States. National Center for Health Statistics, USA, 2007. www.cdc.gov/nchs/hus.htm

2 Collin BA, Ramphal R. Pneumonia in the compromised host including cancer patients and transplant patients. Infect Dis Clin North Am 1998; 12: 781-805.
3 Rañó A, Agustí C, Benito N, et al. Prognostic factors of nonHIV immunocompromised patients with pulmonary infiltrates. Chest 2002; 122: 253-261.

4 Pizzo PA. Fever in immunocompromised patients. N Engl J Med 1999; 341: 893-900.

5 Jones RN. Contemporary antimicrobial susceptibility patterns of bacterial pathogens commonly associated with febrile patients with neutropenia. Clin Infect Dis 1999; 29: 495-502.

6 Mandell LA, Wunderink RG, Anzueto A, et al. Consensus guidelines on the management of community-acquired pneumonia in adults. Clin Infect Dis 2007; 44: Suppl. 2, S27-S72.

7 Rosenow EC III. Diffuse pulmonary infiltrates in the immunocompromised host. Clin Chest Med 1990; 11: 55.

8 Williams DM, Krick JA, Remington JS. Pulmonary infection in the compromised host: part I. Am Rev Respir Dis 1976; 114: 359.

9 Niederman MS, Mandell LA, Anzueto A, et al. Guidelines for the management of adults with community-acquired pneumonia. Diagnosis, assessment of severity, antimicrobial therapy, and prevention. Am J Respir Crit Care Med 2001; 163: 1730-1754.

10 Community-Acquired Pneumonia Organization (CAPO). www.caposite.com Accessed and updated daily.

11 Hübel K, Hegener K, Schnell R, et al. Suppressed neutrophil function as a risk factor for severe infection after cytotoxic chemotherapy in patients with acute nonlymphocytic leukemia. Ann Hematol 1999; 78: 73.

12 Kumashi P, Girgawy E, Tarrand JJ, Rolston KV, Raad II, Safdar A. Streptococcus pneumoniae bacteremia in patients with cancer: disease characteristics and outcomes in the era of escalating drug resistance (1998-2002). Medicine (Baltimore) 2005; 84: 303-312.

13 Velasco E, Byington R, Martins CA, Schirmer M, Dias LM, Goncalves VM. Comparative study of clinical characteristics of neutropenic and non-neutropenic adult cancer patients with bloodstream infections. Eur J Clin Microbiol Infect Dis 2006; 25: 1-7.

14 Kress JP, Christenson J, Pohlman AS, Linkin DR, Hall JB. Outcomes of critically ill cancer patients in a university hospital setting. Am J Respir Crit Care Med 1999; 160: 1957-1961.

15 Azoulay E, Moreau D, Alberti C, et al. Predictors of shortterm mortality in critically ill patients with solid malignancies. Intensive Care Med 2000; 26: 1817-1823.

16 Staudinger T, Stoiser B, Müllner M, et al. Outcome and prognostic factors in critically ill cancer patients admitted to the intensive care unit. Crit Care Med 2000; 28: 1322-1328.

17 Regazzoni CJ, Irrazabal C, Luna CM, Poderoso JJ. Cancer patients with septic shock: mortality predictors and neutropenia. Support Care Cancer 2004; 12: 833-839.

18 Brunet F, Lanore JJ, Dhainaut JF, et al. Is intensive care justified for patients with haematological malignancies? Intensive Care Med 1990; 16: 291-297.

19 Hughes WT, Armstrong D, Bodey GP, et al. 1997 guidelines for the use of antimicrobial agents in neutropenic patients with unexplained fever. Infectious Diseases Society of America. Clin Infect Dis 1997; 25: 551-573.

20 National Comprehensive Cancer Network. Prevention and treatment of cancer-related infections. 2007. www.nccn.org/ about/news/newsinfo.asp?newsID $=107$ 